\title{
Column Strengthening with TRC: Influences of the Column Geometry onto the Confinement Effect
}

\author{
Regine Ortlepp, Andy Lorenz, and Manfred Curbach \\ Institute of Concrete Structures, Technische Universität Dresden, Dresden 01062, Germany \\ Correspondence should be addressed to Regine Ortlepp, regine.ortlepp@tu-dresden.de
}

Received 25 July 2009; Accepted 19 December 2009

Recommended by Chun-Hway Hsueh

\begin{abstract}
The increase of the load-carrying capacity of columns being reinforced with Textile Reinforced Concrete (TRC) is partly achieved by the additional concrete cover. But then it is also decisively caused by the confinement effect of the textile reinforcement. The confinement is thereby producing a three-axial state of stress within the concrete core of the column. The effectiveness of such a confinement is especially dependent on the geometry of the concrete column to be strengthened. At rectangular ones with sharp edges without ogees the TRC strengthening can only augment the load-carrying concrete share not create a confinement effect which can be achieved at the round counterparts. Within the study we tested columns with all possible cross-sections from square to circle with different transition radiuses. Thus the influence of the transition radius onto the local-bearing capacity of the reinforcing textile was recorded. Furthermore the impact of different fibre materials and reinforcement degrees of the TRCstrengthening layer has been examined. The first results show a considerable disproportionate increase of the confinement effect with rising transition radius, as well as a growth of the confinement effect with augmenting level of reinforcement in the TRCstrengthening layer.
\end{abstract}

Copyright () 2009 Regine Ortlepp et al. This is an open access article distributed under the Creative Commons Attribution License, which permits unrestricted use, distribution, and reproduction in any medium, provided the original work is properly cited.

\section{Introduction}

Caused by conversions of existing buildings, it is often necessary to strengthen the structure. This can become necessary when the structural safety has to be restored after a fire or an earthquake. Columns are elements of special importance for the static system of many buildings.

In praxis there are already different strengthening methods in use. Shotcrete enables a big part of the increase of the load-carrying capacity by the bearing capacity of the additional longitudinal steel reinforcement and the additional concrete layer. This kind of strengthening, though, is connected with a considerable growth of the column size due to the necessary concrete cover for the new steel reinforcement. Strengthenings out of carbon fibre laminate (CFRP sheets) keep the basic component size to a large extent. However the reinforcement effect here is only achieved by the confinement of the core concrete of the column. TRC can combine the advantages of the two previously mentioned strengthening methods adequately.
The Ultimate load enhancement with TRC results from the cross-section elevation owing to the additionally applied concrete layer and the confinement effect of the strengthening coat. Previous examinations have shown that a confinement effect can be activated at round columns while at rectangular ones with sharp edges that was not to be seen (Ortlepp et al. [1]). Triantafillou et al. [2] report, as well, that the bearing capacity increase of a textile concrete strengthening is more effective at round columns than at their counterparts with a square cross-section. This article shows how the confinement effect can be activated at square columns, as well, by rounding the edges.

\section{Test Specimen and Test Setup}

2.1. Geometry. Within this study we observed short columns with a height of $300 \mathrm{~mm}$. The cross-section has been regarded from a square with $150 \mathrm{~mm} \times 150 \mathrm{~mm}$ (test specimen no. 1) to a circle with a diameter of $150 \mathrm{~mm}$ (test specimen no. 6) (refer to Figure 1, parameter axis (1)). 
TABLE 1: Overview over the test series.

\begin{tabular}{|c|c|c|c|c|c|c|}
\hline \multirow[b]{2}{*}{ Series no. } & \multicolumn{6}{|c|}{ Strengthening } \\
\hline & Material & $\begin{array}{c}\text { Fineness } \\
(\text { tex })\end{array}$ & $\begin{array}{c}\text { Distance } \\
(\mathrm{mm})\end{array}$ & $\begin{array}{c}\text { Cross section } \\
\left(\mathrm{mm}^{2} / \mathrm{m}\right)\end{array}$ & Layers & $\begin{array}{l}\text { Stiffness } \\
(\mathrm{MN} / \mathrm{m})\end{array}$ \\
\hline 1 & none & - & - & - & - & - \\
\hline 2 & fine-gr. conc. & - & - & - & 0 & - \\
\hline 3 & AR-glass & 1,200 & 7.2 & 61.1 & 6 & 27.3 \\
\hline 4 & carbon & 800 & 7.2 & 62.5 & 2 & 27.9 \\
\hline 5 & carbon & 3,500 & 10.8 & 179.6 & 3 & 109.9 \\
\hline
\end{tabular}

The transition radius has been augmented evenly by steps of $15 \mathrm{~mm}$.

A further test specimen (7) was concipated in order to examine size effects. The geometry was picked, thus, that with a smaller edge length $a=20 \mathrm{~mm}$ the radius $r$ corresponds to a previously examined test specimen (parameter axis (2)) while the proportion between radius and edge length $r / a$ corresponds to another previously tested one (parameter axis (3)). Thereby we could record data for the influence of the relation between transition radius and edge length (parameter axis (2)) as well as the impact of the radius at equal geometry proportion (parameter axis (3)).

2.2. Materials. The columns to be strengthened consisted of plain normal concrete with a maximum aggregate diameter of $8 \mathrm{~mm}$. The average compressive strength of the cubes after 28 days was $30 \mathrm{~N} / \mathrm{mm}^{2}$.

The TRC-strengthening layer consists of two main components-fine grained concrete and textile reinforcement structures. The fine grained concrete forms the matrix with a maximum aggregate diameter of $1 \mathrm{~mm}$. The average prism compressive strength according to DIN EN 101511 [3] has been at about $80 \mathrm{~N} / \mathrm{mm}^{2}$.

The low tensile strength of the fine grained concrete is compensated by the efficient textile reinforcement-just as it is the case with the common reinforced concrete. These strengthening structures consist of long carbon or alkali resistant glass fibres (Figure 2), taking the forces set free within the concrete during crack formation.

Three different textile reinforcement fabrics were used to strengthen the columns. The first was a biaxial one out of alkali resistant glass (AR glass) with a fineness of 1.200 tex (meaning $1.200 \mathrm{~g}$ per $\mathrm{km}$ length of the fibre) and a filament distance of $7.2 \mathrm{~mm}$ within main bearing direction (Figure 2(a)). The yarns (fibres) in transverse direction only serve as stabilisation within the textile fabric. The crosssectional area of a yarn in main bearing direction was about $0.44 \mathrm{~mm}^{2}$, Young's modulus $74,450 \mathrm{~N} / \mathrm{mm}^{2}$, and the tensile strength $1,232 \mathrm{~N} / \mathrm{mm}^{2}$.

The second textile was a biaxial fabric with carbon fibres with a fineness of 800 tex and a filament distance of $7.2 \mathrm{~mm}$ in main bearing direction. The cross-sectional area of the carbon yarn was about $0.45 \mathrm{~mm}^{2}$, Young's modulus $222,980 \mathrm{~N} / \mathrm{mm}^{2}$ and the tensile strength $1,032 \mathrm{~N} / \mathrm{mm}^{2}$.

The third one was biaxial fabric with a fineness of 3,500 tex and a filament distance of $10.8 \mathrm{~mm}$ in main bearing direction. The cross-sectional area was about $1.94 \mathrm{~mm}^{2}$ and the Young's modulus 204,000 N/mm².

The yarns of the textile structures consist of many individual filaments (Figure 3 ). During the production process the textile reinforcement has been coated with a styrolbutadiene cover within the textile machine. This improves the compound between the individual filaments in the yarn and results in a higher fibre strength compared to uncoated textiles.

2.3. Test Parameters. The test parameters of the study were the following:

(1) the geometry (refer to Section 2.1),

(2) the collapse load part of the pure fine grained concrete,

(3) the fibre material AR glass or carbon,

(4) the fibre volume percentage.

Five series have been examined in total (Table 1). Every series consisted of two in Section 2.1 explained test specimen each so as to observe the geometry flow. The first series was a reference series out of pure normal concrete without reinforcement. The second one was only strengthened with a fine grained concrete cover without any textile reinforcement, which provides the ultimate load part of the pure fine grained concrete within the reinforcement layer. This carries additional normal forces. In that case no confinement effect is being activated. The third series was strengthened with textile concrete out of AR glass fibre textiles and the fourth with carbon fibres having the same cross-section. By decreasing the textile layers from 6 to 2, a nearly equal stiffness of the confinement reinforcement could be achieved. The fifth series was also strengthened with carbon fibres but here with a considerably higher amount of the fibre volume resulting into a stiffness four times the previous series' one.

2.4. Test Execution. The tests were executed with a compression test machine with a maximum load capacity of $1 \mathrm{MN}$ (Figure 4). The test speed was selected according to Young's modulus test after DIN EN 12390-1 [4]. The tests were carried out deformation controlled in order to be able to examine the course of failure in the core and the reinforcing layers of the test specimen. 


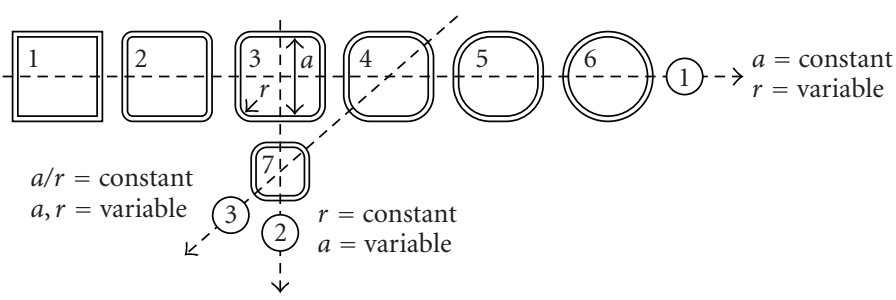

FIGURE 1: Schematic depiction of the connection between the examination parameters.

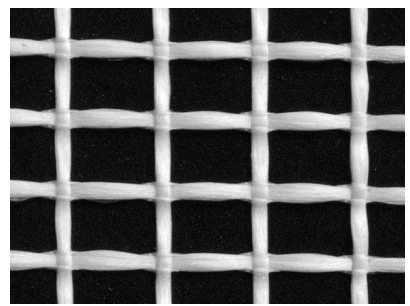

(a) textile out of alkali resistant glass fibres (AR-glass)

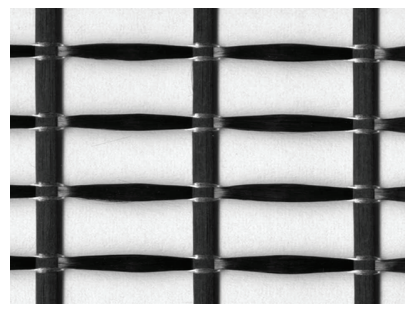

(b) textile out of carbon fibres

Figure 2: Examples of the used reinforcement textiles.

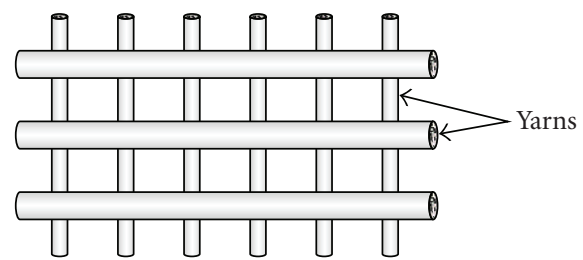

(a) textile

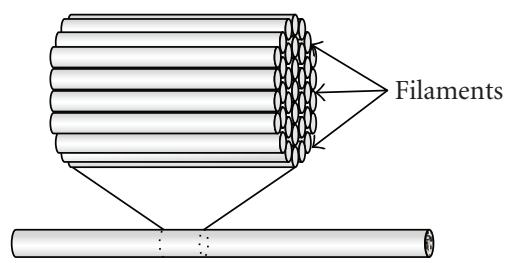

(b) yarn

FIGURE 3: Structure of a reinforcing textile.

\section{Test Results}

The tests showed a load-carrying capacity increase of the columns being possible with Textile-Reinforced Concrete. As shown in Figure 5 the load-carrying capacity is augmenting at all column geometries by textile reinforcing layers (series 3-5) compared to the reference series (1). Displayed is the average value of both tests of the same test specimen geometry within one series. The more the geometry of the column approximates a circle (through rounding of the edges), the higher is the effect of the increased load-carrying capacity. There the Textile-Reinforced concrete shows the same behaviour as FRP strengthenings.

The impact of the individually examined parameters is more obvious in Figure 6. Here the load growth of the

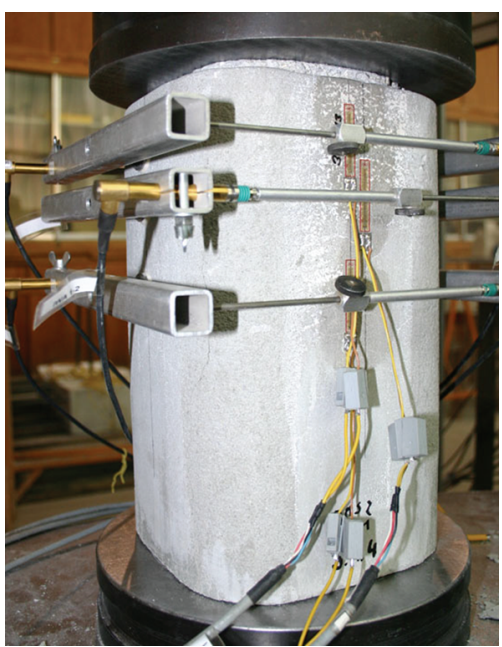

FIgURE 4: Test set-up.

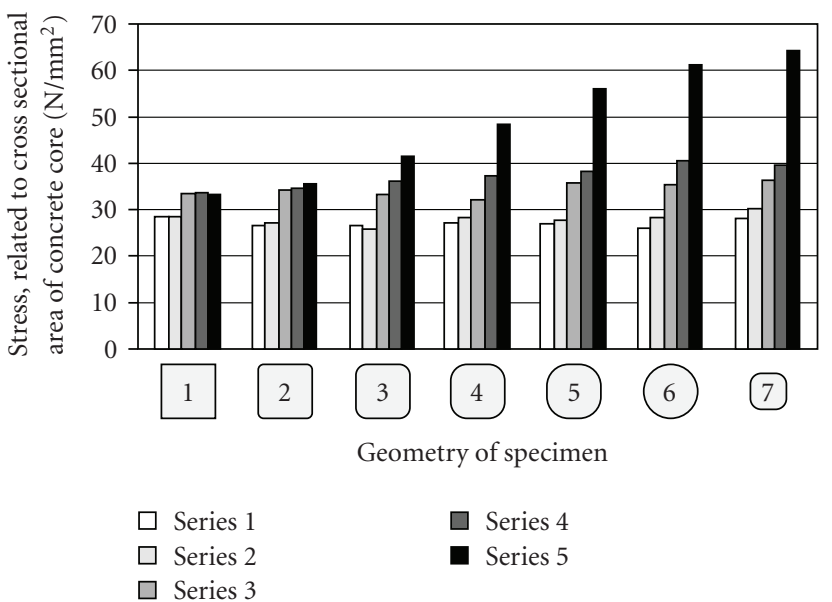

FIGURE 5: Load-carrying capacity of the reinforced columns in dependence of the geometry.

examined series with reinforcement layer is shown compared to the unstrengthened reference series of the matching test specimen geometry. The large influence of the geometry onto the reachable load-bearing capacity raise is distinguishable. There is no ultimate radius for the edge fillet after which the load bearing capacity escalates. Instead the collapse load increases successively with the cross-section becoming more and more a circle. 


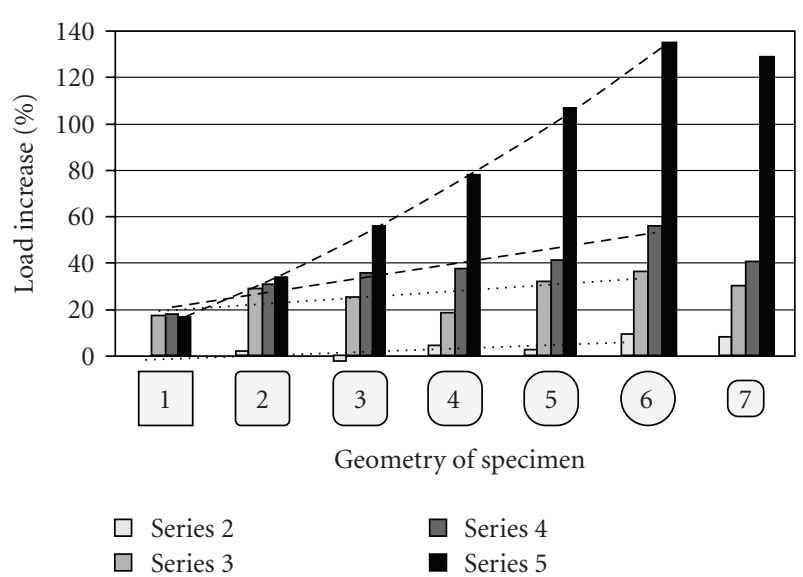

FIGURE 6: Impact of the column geometry onto the increase of the load-bearing capacity.

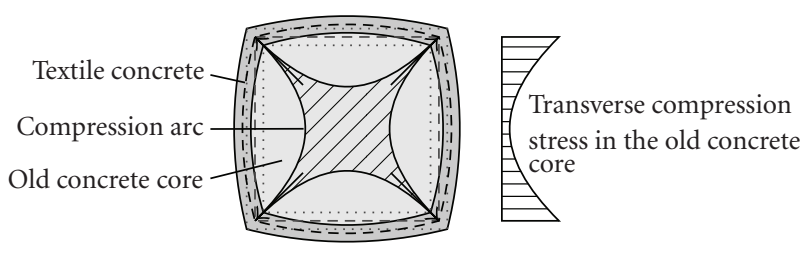

Figure 7: Deformation of the textile concrete frame, schematic (illustration disproportionate).

The ultimate load section of the pure fine grained concrete matrix (series 2) can be assumed to be insignificantly small. This can be justified by the fine grained concrete cracking as soon as the radial tension of the core concrete surpasses the tension strength of the fine grained concrete matrix. What is more it could also be examined at the test with textile reinforcement that after the cracks start forming within the fine grained concrete matrix the reinforcing layer suffered an expansion increase. Coming along with that is the formation of a bond crack between fine grained concrete matrix and concrete core (Ortlepp and Curbach [5]), which results in a further load increase mainly through the confinement effect of the textile reinforcement. At the beginning of this study there were expected to be additive load bearing properties from the normal force of the additional fine-grained concrete layer and the confining effect of the textile reinforcement. Since these two effects occur one after the other and not simultaneously this it not the case.

The effectiveness of the confinement reduces itself from the circle cross-section towards the square one with increasing straight edge length between the edges/radiuses. At that point uneven demands inside the cross-section emerge. The textile reinforcement layer bends itself to the outside in the area between the corners due to the lateral strain of the old concrete core (Figure 7). Thus the area near the straight edge is not confined, but it emerges an arc of pressure forces held up at the corners of the Textile-Reinforced concrete layer.
The evener the tension can be introduced into the TextileReinforced concrete layer the higher the confinement effect.

The test results at the down scaled test specimen no. 7 show an impact of the size effect. Obviously the effect of the confinement is also increasing with the decrease of the size of the core cross-section to be confined. Considering that it is not possible to finally determine which parameter, radius or proportion of radius to side length, has the bigger influence concerning the in 2.1 mentioned parameter axes.

The effect of the fibre material is relatively small with equal stiffness (compare series 3 and 4). The load-carrying capacity increase is thereby a little bit higher with carbon than it is with AR-glass. So as to achieve the same stiffness with carbon compared to AR glass is only needed about a third of its reinforcement amount though. So it is to be realized that carbon has essential advantages for column strengthening compared to AR-glass.

A considerable impact onto the effectiveness of the confinement has the degree of reinforcement. The results clearly show the collapse load rise to increase with a growing amount of reinforcement within the textile reinforcement layer (compare series $4+5$, Figure 6 ). Thus the load-carrying capacity of the circle shaped cross-section at series 6 could be augmented by $135 \%$ meaning an amount 2.35 times higher than at the unstrengthened reference column.

\section{Conclusion}

It is important for a practical use of TRC for strengthening columns to round the edges as far as possible so as to increase the effectiveness of the confinement.

The load-carrying capacity augmentation by a TextileReinforced concrete layer is substantially achieved by the confinement of the core concrete. The load fraction being carried by the normal forces within the fine grained concrete coat is small compared to the confinement effect.

The mentioned statement in paragraph 4 concerning the size effect impact allows the converse argument that the confinement effect should decrease with augmenting crosssectional area if the reinforcement degree remains the same. Since in praxis often also columns with larger cross-sections need to be reinforced more tests regarding that aspect are needed.

The fiber material carbon has obvious advantages as a strengthening material for the reinforcing layer for the confinement of columns due to its higher stiffness compared to AR-glass.

A sensible reinforcement effect is achieved by sufficiently high textile reinforcement degrees.

\section{References}

[1] R. Ortlepp, F. Schladitz, and M. Curbach, “TRC-strengthening for normal and Torsion loads," in Proceedings of the 18th International Conference on Computer Methods in Mechanics (CMM '09), pp. 345-346, Zielona Góra, Poland, May 2009.

[2] T. C. Triantafillou, C. G. Papanicolaou, P. Zissimopoulos, and T. Laourdekis, "Concrete confinement with textile-reinforced 
mortar jackets," ACI Structural Journal, vol. 103, no. 1, pp. 2837, 2006.

[3] DIN EN 1015 11, Prüfverfahren für Mörtel für Mauerwerk. Teil 11: Bestimmung der Biegezug- und Druckfestigkeit von Festmörtel, Beuth, Berlin, Germany, 2007.

[4] DIN EN 12390-1, Prüfung von Festbeton. Teil 1: Form, Maße und andere Anforderungen für Probekörper und Formen, Beuth, Berlin, Germany, 2001.

[5] R. Ortlepp and M. Curbach, "Strengthening of columns using textile reinforced concrete," Beton- und Stahlbetonbau, vol. 104, no. 10, pp. 681-689, 2009 (German). 

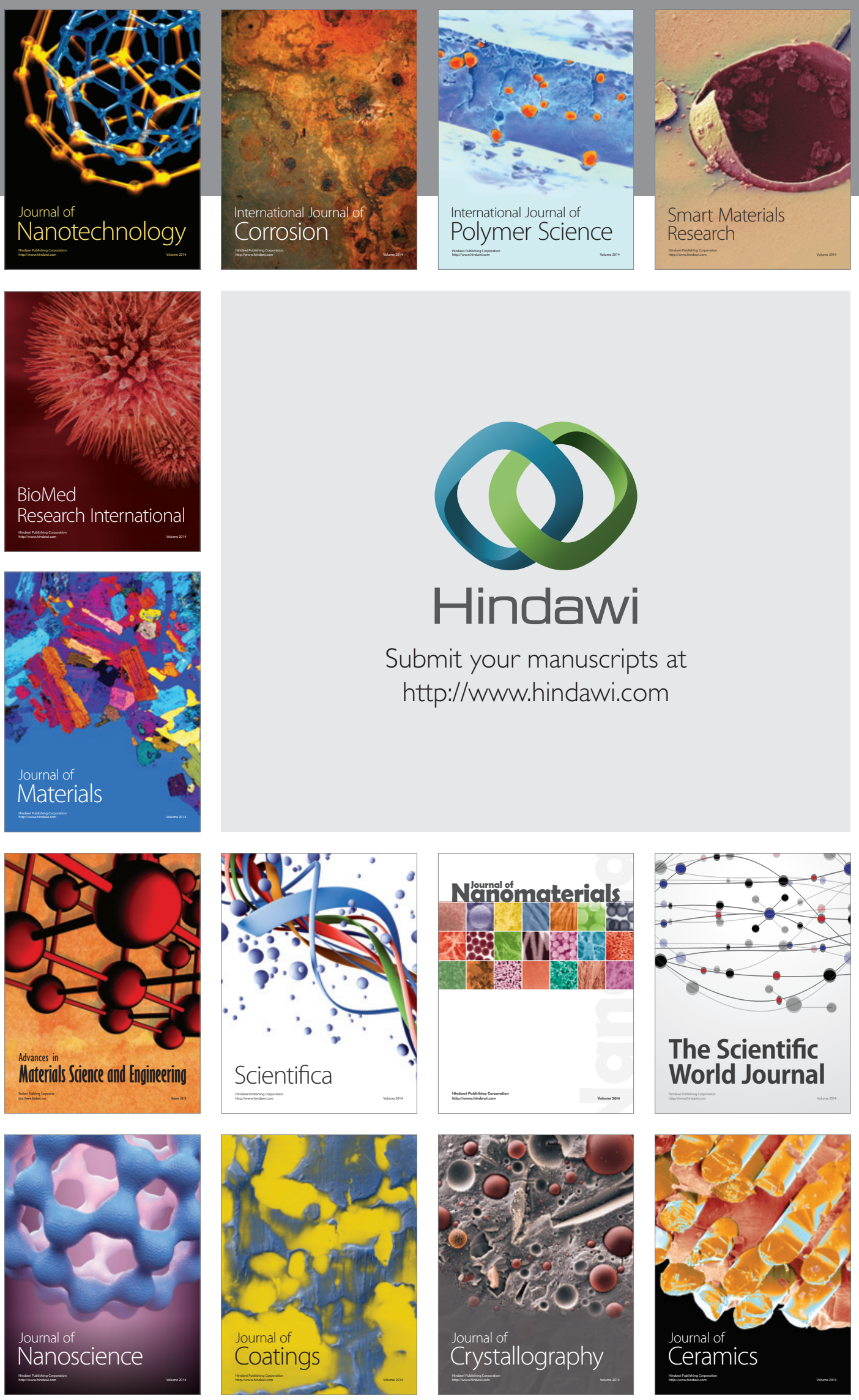

The Scientific World Journal

Submit your manuscripts at

http://www.hindawi.com

\section{World Journal}

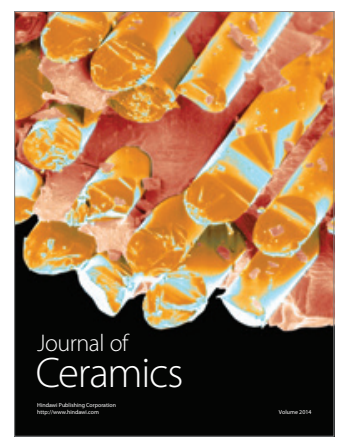

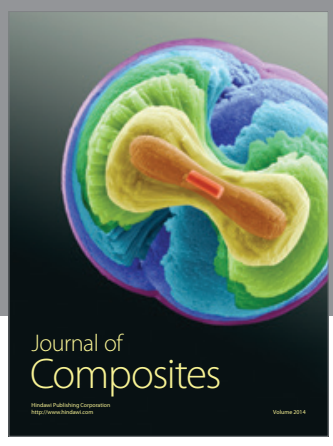
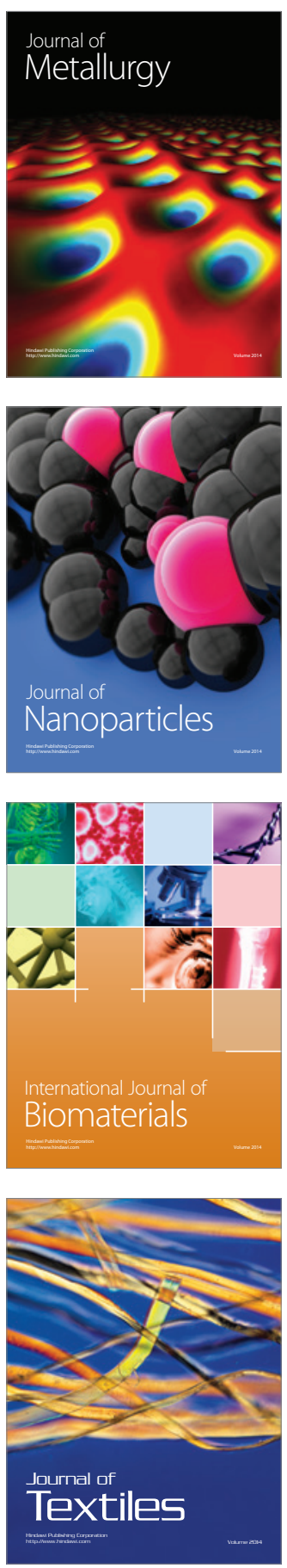